\title{
A CROSS-SECTIONAL STUDY OF CRYPTOCOCCAL ANTIGENEMIA IN ANTI-RETROVIRAL NAIVE HIV INFECTED PATIENTS
}

\author{
Saramma Mini Jacob¹, Sekkizhar Geethalakshmi², Fatima Bathool Rani3 ${ }^{3}$, Sivasangeetha Karthikeyan4, Thatchinamoorthy Gopal5, \\ Sathishkumar Elumalai ${ }^{6}$
}

1 Professor, Department of Experimental Medicine, The Tamilnadu Dr. MGR Medical University, Chennai.

2Vice Chancellor, The Tamilnadu Dr. MGR Medical University, Chennai.

3 Postgraduate Student, Department of Microbiology, Government Thanjavur Medical College, Thanjavur.

${ }_{4}^{4}$ Associate Professor, Department of Experimental Medicine, The Tamilnadu Dr. MGR Medical University, Chennai.

${ }^{5}$ Lab. Technologist, Department of Experimental Medicine, The Tamilnadu Dr. MGR Medical University, Chennai.

${ }^{6}$ Research Associate, Department of Experimental Medicine, The Tamilnadu Dr. MGR Medical University, Chennai.

\begin{abstract}
BACKGROUND
Identification and treatment of opportunistic infections in HIV positive patients is as important as antiretroviral therapy (ART) in improving quality of life and increasing their survival. Despite the widespread use of ART, Cryptococcus remains a significant pathogen among persons infected with HIV. Screening for this fungus will prevent morbidity, mortality and immune reconstitution inflammatory syndrome (IRIS).

The aim of this study was to screen for Cryptococcus neoformans antigen in the sera of ART naive HIV seropositive patients.
\end{abstract}

\section{MATERIALS AND METHODS}

A total of 100 antiretroviral naive HIV positive adults were enrolled in this prospective cross-sectional study. This study was conducted in a tertiary care hospital in Tamilnadu from September 2012 to September 2013. After obtaining written informed consent, serum samples were collected and screened for Cryptococcus neoformans antigen using latex agglutination antigen detection kit (CALAS, USA) as per manufacturer's instructions. Basic demographics such as age, sex and CD4 counts were recorded.

\section{RESULTS}

Among the 100 HIV positive adults enrolled, 56\% were males and 44\% were females. Their age ranged from $20-70$ years with a mean of 40 years; $15 \%$ were positive for cryptococcal antigen. Almost $40 \%$ of HIV patients with Cryptococcal antigenemia had CD4 counts below 350 cells $/ \mathrm{mm}^{3}$.

\section{CONCLUSION}

Cryptococcal antigen screening among ART naive HIV positive patients will help in reducing the morbidity and mortality. Early detection and treatment may be the most cost-effective and easily implemented approach to improve the clinical outcomes.

\section{KEYWORDS}

Cryptococcus; Cryptococcal Antigenemia; HIV; ART.

HOW TO CITE THIS ARTICLE: Jacob SM, Geethalakshmi S, Rani FB, et al. A cross-sectional study of cryptococcal antigenemia in anti-retroviral naive HIV infected patients. J. Evolution Med. Dent. Sci. 2017;6(90):6330-6332, DOI: 10.14260/jemds/2017/1377

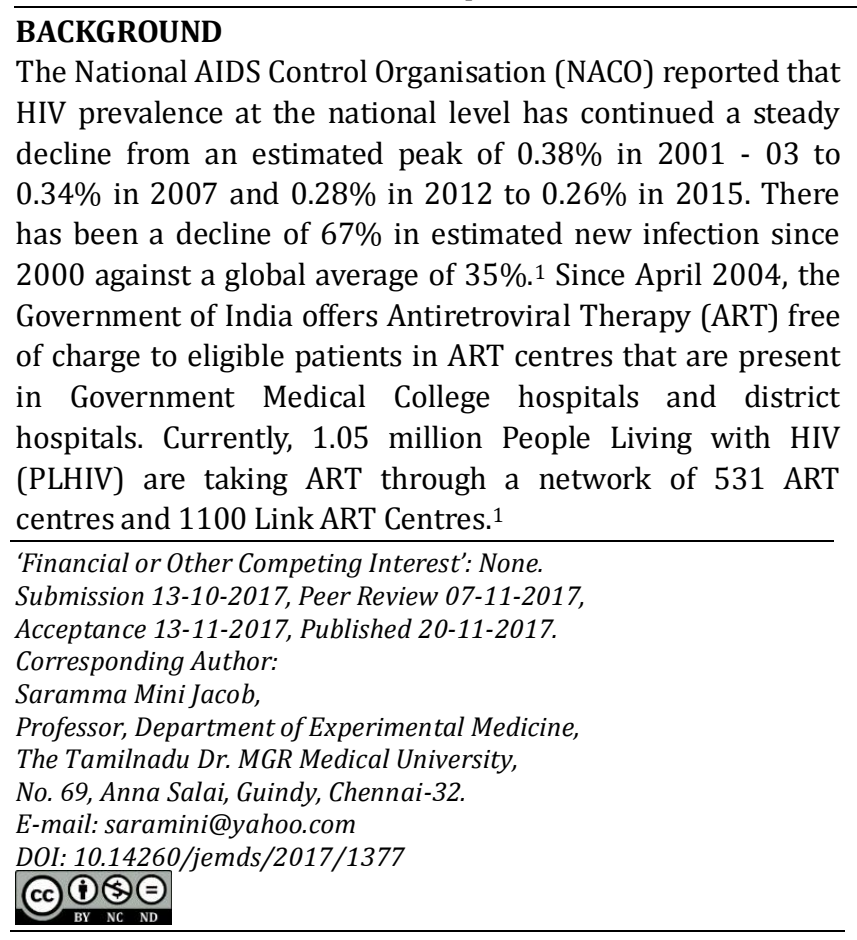
From May 2017, the Government of India has decided to treat all PLHIV with ART irrespective of the CD4 counts, clinical stage, age and population. ${ }^{2}$ The identification and treatment of opportunistic infections is as important as initiating ART in reducing morbidity and mortality in PLHIV. Sometimes, ART can lead to an aberrant inflammatory response and paradoxical clinical worsening known as Immune Reconstitution Inflammatory Syndrome (IRIS). ${ }^{3}$ This is due to subclinical opportunistic infections and disease exacerbations after starting ART. Therefore, screening for opportunistic infections is important in preventing IRIS.

Cryptococcosis is an important opportunistic infection and a major problem for people with advanced HIV/ AIDS. Cryptococcus most commonly infects the central nervous system and lungs of immunocompromised patients and rarely affects optic nerve, bone, liver and lymph node. ${ }^{4}$ Cryptococcal meningitis is one of the most common fungal infections in AIDS patients and has the mortality rate of $25 \%-30 \% .^{5}$ Worldwide, nearly one million cases of HIV-associated cryptococcal meningitis occur each year, resulting in 625,000 deaths. ${ }^{6}$ Despite the widespread use of Highly Active Antiretroviral Therapy (HAART), Cryptococcus remains a 
significant pathogen among persons infected with HIV. The incidence and mortality rate of cryptococcosis are extremely high in resource limited settings. ${ }^{7}$ Unfortunately, screening for this fungus prior to the symptoms and infection has been very limited in India. This study was designed to screen for Cryptococcus neoformans in the serum of ART naive HIV positive patients.

\section{MATERIALS AND METHODS}

This was a prospective cross-sectional study conducted from September 2012 to September 2013. Consenting HIV positive ART naive individuals attending the ART centre at a Government Tertiary Care Hospital in Thanjavur, Tamilnadu were enrolled. Written informed consent was obtained from the study participants after full explanation of the study. Patients on ART and antenatal mothers were excluded from this study. The study was assessed and approved by the Institutional Ethics Committee.

Blood sample (5 mL) was collected by venepuncture under aseptic precautions. Serum was separated and stored at $-70^{\circ} \mathrm{C}$ until further testing. Prior to freezing, $1 \mathrm{~mL}$ of serum was transported to the Department of Experimental Medicine of the Tamilnadu Dr. MGR Medical University for screening of Cryptococcus neoformans antigen. The test was performed using latex agglutination antigen detection kit (CALAS, USA) as per manufacturer's instructions. Latex particles coated with anticryptococcal globulin reacts with cryptococcal polysaccharide antigen causing visible agglutination. Demographics such as age, gender and CD4 counts were recorded.

\section{RESULTS}

Among the 100 HIV positive adults enrolled, 56/100 were males (56\%) and 44\% were females. Their age ranged from 20 - 70 years with a mean of 40 years \pm 11 .8. Fifteen $(15 / 100)$ of them were positive for cryptococcal antigen (Table 1). The CD 4 counts in this study ranged from 121 - 978 cells $/ \mathrm{mm}^{3}$ and the median CD4 count was 564 cells $/ \mathrm{mm}^{3}$. There was no correlation between Cryptococcal antigenemia and CD4 counts. However, $40 \%$ of HIV patients with Cryptococcal antigenemia had CD4 counts below 350 cells $/ \mathrm{mm} 3$.

\begin{tabular}{|c|c|c|c|c|}
\hline Gender & $\begin{array}{c}\text { Cryptococcal } \\
\text { Antigen } \\
\text { Positive }\end{array}$ & $\begin{array}{c}\text { Cryptococcal } \\
\text { Antigen } \\
\text { Negative }\end{array}$ & Total & P value \\
\hline Female & 6 & 38 & 44 & \\
\cline { 1 - 4 } Male & 9 & 47 & 56 & \multirow{2}{*}{0.785} \\
\hline Total & $\mathbf{1 5}$ & $\mathbf{8 5}$ & $\mathbf{1 0 0}$ & \\
\hline \multicolumn{2}{|l}{ Table 1. Gender-Wise Distribution of Cryptococcal Antigen } \\
\hline
\end{tabular}

\section{DISCUSSION}

In 1950s, cryptococcosis was reported in less than 500 patients globally. With the emergence of HIV/ AIDS pandemic, there was an increase in the number of individuals infected with Cryptococcus. ${ }^{8}$ Other risk groups for cryptococcosis are transplant recipients on immunosuppressants and those with haematopoietic or other malignancies, advanced renal or liver disease, solid organ malignancy, sarcoidosis, rheumatologic disease and diabetes mellitus. ${ }^{9-11}$

Detection of cryptococcal antigen in serum can be used as a presumptive diagnosis of cryptococcal meningitis. ${ }^{12}$ An overall prevalence of $15 \%$ of cryptococcal antigenemia was observed in our study. Studies from Nigeria (12.7\%), ${ }^{13}$ Ethiopia (14.2\%), ${ }^{14}$ Congo (15.2\%), ${ }^{15}$ Bangkok (12.9\%) ${ }^{16}$ and Uganda $(19 \%)^{17}$ revealed the prevalence of cryptococcal antigenemia was similar to our study. A recent study from South India documented $88.7 \%$ of patients with cryptococcal meningitis had HIV infection. ${ }^{9}$ Another study from South India in the year 1996 observed 43.9\% of patients with cryptococcal meningitis were HIV positive and reported that there has been a parallel increase in the incidence of HIV and cryptococcal infections. ${ }^{18}$ A study from Indonesia documented a weak correlation between CD4 cell counts and the titre of cryptococcal antigen. ${ }^{19}$ Whereas in the present study there was no correlation; however, the titre of cryptococcal antigen could not be estimated due to limited resources.

A study from Durban, South Africa estimated 14.7\% prevalence of cryptococcal antigen (CrAg) among participants with $\mathrm{CD} 4>200 / \mathrm{mm}^{3}$. This was significantly higher than those with $\mathrm{CD} 4 \leq 200 / \mathrm{mm}^{3}(7.5 \%) .{ }^{20}$ While in the present study, $40 \%$ of HIV patients with Cryptococcal antigenemia had CD4 counts below 350 cells $/ \mathrm{mm}^{3}$. But as per WHO recommendations, cryptococcal screening is considered prior to ART initiation in patients with CD4 counts of less than 100 cells $/ \mathrm{mm}^{3}$. When this recommendation is followed in our setup, many patients with cryptococcal antigenemia are likely to be missed. When ART was initiated in HIV positive patients with undiagnosed cryptococcal disease, they are at risk of developing IRIS and may result in death. ${ }^{21}$ Pre-emptive antifungal treatment can be offered to HIV positive patients with cryptococcal antigenemia that will halt the development of cryptococcal meningitis.

The main limitation of this study was that clinical manifestations were not recorded. Studies with more samples size could have enlightened the importance of cryptococcal antigenemia screening in our setting and especially when ART is offered to all HIV positives.

\section{CONCLUSION}

To conclude, this study demonstrated high positivity of cryptococcal antigen among HIV positive ART naive patients. We suggest screening of cryptococcal antigen in all HIV positive patients irrespective of their CD4 counts before starting ART.

\section{ACKNOWLEDGEMENTS}

The authors thank all the study participants and The Tamilnadu Dr. MGR Medical University for the financial support for the study.

\section{REFERENCES}

[1] National AIDS Control Organization (NACO) NEWS. http://naco.gov.in/sites/default/files/Final\%20Englis h\%20Newsletter\%20April-June\%20-Final.pdf

[2] Revised Guidelines on initiation of Antiretroviral Therapy http://naco.gov.in/sites/default/files/Scan_OM\%20CS T.pdf

[3] Meireles M, Moura SC, França M. Immune reconstitution inflammatory syndrome: opening Pandora's box. Article ID 5409254, Case Rep Infect Dis 2017;2017: p. 9. 
[4] Firth GB, Ntanjana T, Law T. Cryptococcal osteomyelitis in a clinically immune-competent child. South Afr J Infect Dis 2015;30(4):138-40.

[5] Dzoyem JP, Kechia FA, Ngaba GP, et al. Prevalence of cryptococcosis among HIV-infected patients in Yaounde, Cameroon. Afr Health Sci 2012;12(2):12933.

[6] Cogliati M. Global molecular epidemiology of Cryptococcus neoformans and Cryptococcus gattii: an atlas of the molecular types. Article ID 675213, Scientifica 2013;2013: p. 23.

[7] Tenforde MW, Wake R, Leeme T, et al. HIV-Associated cryptococcal meningitis: bridging the gap between developed and resource-limited settings. Curr Clin Microbiol Rep 2016;3:92-102.

[8] Pyrgos V, Seitz AE, Steiner CA, et al. Epidemiology of Cryptococcal meningitis in the US: 1997-2009. PLoS One 2013;8(2):e56269.

[9] Abhilash KP, Mitra S, Arul JJ, et al. Changing paradigm of cryptococcal meningitis: an eight-year experience from a tertiary hospital in South India. Indian J Med Microbiol 2015;33(1):25-9.

[10] Brizendine KD, Baddley JW, Pappas PG. Predictors of mortality and differences in clinical features among patients with Cryptococcosis according to immune status. PLoS One 2013;8(3):e60431.

[11] Bernard C, Maucort-Boulch D, Varron L, et al. Cryptococcosis in sarcoidosis: cryptOsarc, a comparative study of 18 cases. QJM 2013;106(6):52339.

[12] Boulware DR, Rolfes MA, Rajasingham R, et al. Multisite validation of cryptococcal antigen lateral flow assay and quantification by laser thermal contrast. Emerg Infect Diseases 2014;20(1):45-53.

[13] Osazuwa OF, Dirisu O, Okuonghae E. Cryptococcal antigenemia in anti-retroviral naïve AIDS patients: prevalence and its association with CD4 cell count. Acta Med Iran 2012;50(5):344-7.

[14] Beyene T, Woldeamanuel Y, Asrat D, et al. Comparison of cryptococcal antigenemia between antiretroviral naïve and antiretroviral experienced HIV positive patients at two hospitals in Ethiopia. PLoS One 2013;8(10): e75585.

https://doi.org/10.1371/journal.pone.0075585
[15] Rajasingham R, Smith RM, Park BJ, et al. Global burden of disease of HIV-associated cryptococcal meningitis: an updated analysis. Lancet Infect Dis 2017;17(8):87381.

[16] Pongsai P, Atamasirikul K, Sungkanuparph S. The role of serum cryptococcal antigen screening for the early diagnosis of cryptococcosis in HIV-infected patients with different ranges of CD4 cell counts. J Infect 2010;60(6):474-7.

[17] Oyella J, Meya D, Bajunirwe F, et al. Prevalence and factors associated with cryptococcal antigenemia among severely immunosuppressed HIV-infected adults in Uganda: a cross-sectional study. J Int AIDS Soc 2012;15(1):15.

[18] Khanna N, Chandramuki A, Desai A, et al. Cryptococcal infections of the central nervous system: An analysis of predisposing factors, laboratory findings and outcome in patients from South India with special reference to HIV infection. J Med Microbiol 1996;45(5):376-9.

[19] Ganiem AR, Indrati AR, Wisaksana $R$, et al. Asymptomatic cryptococcal antigenemia is associated with mortality among HIV-positive patients in Indonesia. J Int AIDS Soc 2014;17(1):18821.

[20] Drain PK, Kleene JM, Losina E, et al. High prevalence of undiagnosed Cryptococcus at HIV diagnosis across the CD4 spectrum in Durban. CROI Conference on retroviruses and Opportunistic Infections 2014. Abstract no. 835.

[21] Larson BA, Rockers PC, Bonawitz R, et al. Screening HIV-infected patients with low CD4 counts for cryptococcal antigenemia prior to initiation of antiretroviral therapy: cost effectiveness of alternative screening strategies in South Africa. PLoS One 2016;11(7): e0158986.

https://doi.org/10.1371/journal.pone.0158986 